\title{
Defective neutrophil function and microbicidal mechanisms in the myelodysplastic disorders
}

\author{
S MARTIN,${ }^{*} \dagger$ SC BALDOCK,${ }^{*} \dagger$ ATM GHONEIM, $\dagger$ JA CHILD* \\ From the *Department of Haematology, Leeds General Infirmary, and the †Department of Microbiology, \\ University of Leeds, Leeds
}

SUMMARY Neutrophil function studies have been carried out in a series of 44 patients with primary myelodysplastic syndromes (MDS). In vitro tests of phagocytosis and killing of Candida guilliermondii and Staphylococcus aureus identified 13 patients with abnormal neutrophil function at presentation and a further 10 who developed abnormalities during the course of their disease. The incidence of defective function in the five disease categories in this series was: refractory cytopenia (RC) $8 / 17$; refractory cytopenia with sideroblastic change (RC + SC) $5 / 8$; acquired idiopathic sideroblastic anaemia (AISA) 2/4; refractory anaemia with excess blasts (RAEB) 7/11; chronic myelomonocytic leukaemia (CMML) 1/4. Eleven of 23 patients with defective neutrophil function experienced severe infective complications; in only three of these patients were neutrophil counts $<1 \times 10^{9} / 1$ and susceptibility to infection was considered to reflect, at least partially, qualitative neutrophil abnormalities. There was no correlation between absolute neutrophil count and defective function. Abnormal overall neutrophil microbicidab activity was equally associated with impaired and normal phagocytosis. Some patients witto intracellular killing defects had reduced myeloperoxidase (MPO) activities and one had reduced hexose monophosphate shunt (HMPS) activity. In two patients, whose neutrophils showed mar? kedly impaired candidacidal activity, levamisole corrected function when added in vitro at $10^{-7} \mathrm{M}$ and also when administered in therapeutic dosage. It is suggested that deranged function, probably reflecting abnormalities in maturation of the granulocyte series, occurs across the myelodysplastic spectrum and that several microbicidal mechanisms may be defective.

Neutrophil abnormalities are recognised as one feature of "preleukaemia." Neutropenia is common and hypogranularity and Pelger-Huet-like changes are frequently observed in blood films. ${ }^{12}$ An increased susceptibility to infection which is not necessarily simply a reflection of neutropenia (if present) has been noted and neutrophil dysfunction suggested as an underlying cause. ${ }^{34}$ The data substantiating this are sparse but clear-cut bactericidal and candidacidal defects have been described, notably by Breton-Gorius et al.$^{45}$ Although there are other reports of clinically significant microbicidal defects in such patients, ${ }^{5-8}$ the numbers investigated have been small.

It is now apparent that there is a spectrum of related disease states which include "preleukaemia" but which show considerable variation in the risk of transformation to a blastic phase. ${ }^{910}$ The range of

Accepted for publication 1 June 1983 disorders have been collectively described as comprising the myelodysplastic syndromes (MDS). In the French-American-British (FAB) Co-operative Group classification ${ }^{10}$ there are four basic categories: (i) refractory anaemia (RA); (ii) RA with ring sideroblasts (to include acquired sideroblastic anaemia (AISA); (iii) RA with excess blasts (RAEB) and (iv) chronic myelomonocytic leukaemia (CMML): a fifth category, RAEB in transformation has also been recognised recently. ${ }^{10}$ Evidence of dysgranulopoiesis is seen particularly in $\sigma$ RAEB but similar features may be found in the $N$ other disorders. In RA, where the marrow is normoor hypercellular and shows dysmyelopoietic features without excess of blast cells, anaemia is not invariable: neutropenia and/or thrombocytopenia may be the dominant features and, for this reason, we have preferred the term refractory cytopenia (RC) to describe this group. We have also distinguished between RC with sideroblastic change and AISA 
without discernible abnormalities in granulopoiesis or thrombopoiesis (as assessed by light microscopy). The present study, of 44 patients, was initiated because of the need for an investigation of the neutrophil function of a larger series of patients across the MDS spectrum of disorders; the principal aims were to assess the incidence of defective phagocytosis and intracellular killing of bacteria and fungi and to compare the findings in the definable categories. The further investigation and treatment of some of these patients also provided data relating to possible underlying abnormal microbicidal mechanisms.

\section{Material and methods}

Forty-four patients with myelodysplastic syndromes (MDS) were investigated. Their ages ranged from 40 to 87 (mean 65) yr. The following categories were distinguished on the basis of peripheral blood and bone marrow films examined by light microscopy: refractory cytopenia (RC) (17 patients); refractory cytopenia with sideroblastic change (RC + SC) (8 patients); acquired idiopathic sideroblastic anaemia (AISA) (4 patients); refractory anaemia with excess blasts (RAEB) (11 patients); chronic myelomonocytic leukaemia (CMML) (4 patients) (Table 1). Neutrophil function studies were in many cases carried out longitudinally during the course of the disease as well as at the time of diagnosis; the period of follow-up, which in some cases was as long as two years, averaged three months. Neutrophil function tests were not carried out during episodes of clinically or microbiologically diagnosed infection because of the possibility of misleading results. Neutrophils from patients were always tested in parallel with neutrophils from normal control subjects (chiefly laboratory staff volunteers). Control data obtained over a period of three years was also used in the statistical method for determining the indices of function.

Table 1 Patient categories

\begin{tabular}{ll}
\hline Diagnosis & Patients \\
\hline RC & AG, AM, ES, MS, FW, TD, EW, FL, \\
& BR, PW, RW, GC, DK, KK, JW, KM, MG. \\
MG. & ED, EL, MC, HTh, JH, DS, CS, HJ. \\
RC + SC & RL, WS, HP, DB. \\
AISA & MF, HD, PF, AH, JM, SS, JB, MCh, \\
RAEB & BB, IM, HT. \\
CMML & JJ, JS, JSt, MM. \\
\hline RC & $=$ refractory cytopenia. \\
RC + SC = refractory cytopenia with sideroblastic change. \\
AISA $=$ acquired idiopathic sideroblastic anaemia. \\
RAEB = refractory anaemia with excess blasts. \\
CMML = chronic myelomonocytic leukaemia.
\end{tabular}

NEUTROPHIL PREPARATION

Heparinised blood samples were sedimented in Dextran and the neutrophils separated from the leucocyte-plasma by centrifugation over FicollIsopaque, SG 1.077. ${ }^{11}$ The neutrophils were washed twice in Hank's balanced salt solution (HBSS) and resuspended to $5 \times 10^{6}$ neutrophils $/ \mathrm{ml}$. The leucocyte suspension was $>90 \%$ neutrophils with viability by trypan blue dye exclusion $>95 \%$.

\section{SERUM}

Pooled $\mathrm{AB}$ serum from healthy donors, stored in liquid nitrogen $\left(-196^{\circ} \mathrm{C}\right)$, was used in all assays.

\section{NEUTROPHIL FUNCTION STUDIES}

All incubations were carried out at $37^{\circ} \mathrm{C}$ on an orbital shaker $(170 \mathrm{rpm})$.

A microscopic candidacidal assay involved the examination of smears prepared from a mixture of Candida guilliermondii and neutrophils incubated for $60 \mathrm{~min}$ at a ratio of $3: 1$ in HBSS $+10 \% \mathrm{AB}$ serum (HBSS-AB). ${ }^{12}$ The smears were stained with May-Grünwald-Giemsa and the number of viable and non-viable candida within 100 neutrophils was counted.

$A{ }^{51}$ chromium release candidacidal assay measured neutrophil candidacidal activity by the release of ${ }^{51}$ chromium from labelled $C$ guilliermondii. ${ }^{14}{ }^{15}$ Triplicate assays were set up comprising $5 \times 10^{5}$ neutrophils and $1.5 \times 10^{6}{ }^{51} \mathrm{Cr} C$ guilliermondii in $0.5 \mathrm{ml}$ HBSS-AB. After $60 \mathrm{~min}$ incubation $0.1 \mathrm{ml}$ sodium deoxycholate $(24 \mathrm{mg} / \mathrm{ml})$ and $0.2 \mathrm{ml}$ DNase $(0 \cdot 1 \mathrm{mg} / \mathrm{ml})$ were added for $15 \mathrm{~min}$ and the tubes then centrifuged for $10 \mathrm{~min}$ at $2000 \mathrm{~g}: 0.2 \mathrm{ml}$ of each supernatant was removed for gamma counting. The results were expressed by the following formula:

$$
\% \text { release }=\frac{X-S}{T-S} \times 100
$$

where $X$ is the radioactivity released in the presence of neutrophils, $S$ is the spontaneous release after incubation in medium, $\mathrm{T}$ is the total radioactivity in $0 \cdot 2 \mathrm{ml}$ of assay mixture.

\section{Phagocytosis of candida}

The technique of Yamamura et $a^{16}$ was adapted for use with $C$ guilliermondii whereby the uptake of ${ }^{3} \mathrm{H}$-uridine by non-ingested organisms was used as a measure of phagocytosis. ${ }^{17}$ Ingested candida were unable to incorporate the uridine. Triplicate assays comprised $5 \times 10^{5}$ neutrophils and $5 \times 10^{6} C$ guilliermondii in $0.5 \mathrm{ml}$ HBSS-AB. Control assays contained candida but no neutrophils. After $30 \mathrm{~min}$ 
incubation $1 \mathrm{mg}$ phenylbutazone in $0.05 \mathrm{ml}$ HBSS was added to the assays to inhibit further phagocytosis. ${ }^{18}$ Duplicate $0.1 \mathrm{ml}$ aliquots were then removed and incubated in microtitre wells containing $5 \mu \mathrm{l}{ }^{3} \mathrm{H}$-uridine $(0.5 \mu \mathrm{Ci}: 5 \mathrm{Ci} / \mathrm{mmol})$. After $30 \mathrm{~min}$ at $37^{\circ} \mathrm{C}, 0.85 \%$ TRIS- $\mathrm{NH}_{4} \mathrm{Cl}$ was added to each well to lyse contaminating red cells. The candida-associated radioactivity was collected on to GF/C glass fibre filters using an automated cell harvester. The filters were washed in water and methanol and placed into NE 233 scintillant for liquid scintillation counting. Results were expressed in terms of the neutrophil-induced inhibition of uridine uptake into candida:

$\%$ inhibition $=$

cpm candida - cpm (candida + neutrophils)

cpm candia

\section{Bactericidal assay}

Duplicate assays comprised $10^{6}$ neutrophils and $10^{7}$ Staphylococcus aureus NCTC 6571 in $0.5 \mathrm{ml}$. HBSS-AB. After 20 min incubation the tubes were put on ice and $4.5 \mathrm{ml}$ sterile distilled water added. Duplicate $0.1 \mathrm{ml}$ aliquots were taken for serial dilution and viable counting to determine the percentage of bacteria killed ${ }^{18}$ at $20 \mathrm{~min}$.

\section{Phagocytosis of bacteria}

The assay mixture comprised $10^{6}$ neutrophils and $10^{7}{ }^{3} \mathrm{H}$-thymidine labelled $S$ aureus in $0.5 \mathrm{ml}$ HBSS-AB. ${ }^{1719}$ Tubes were set up in duplicate to determine:

(a) the total radioactivity in the assay;

(b) percentage phagocytosis of bacteria by neutrophils.

After $20 \mathrm{~min}$ incubation $2 \mathrm{ml}$ phosphate-buffered saline (PBS) were added to tubes (a) which were then centrifuged for $10 \mathrm{~min}$ at $1500 \mathrm{~g}$ to collect all neutrophil and bacteria-associated radioactivity in the cell pellet. Lysostaphin $(5 \mu \mathrm{g})$ and $1 \mathrm{mg}$ phenylbutazone in $0.1 \mathrm{ml}$ HBSS were added to tubes (b) and incubated for $20 \mathrm{~min}$ at $37^{\circ} \mathrm{C}$ to lyse noningested bacteria. After washing twice in PBS for $5 \mathrm{~min}$ at $200 \mathrm{~g}$ the neutrophils and ingested bacteria were resuspended in $0.85 \%$ TRIS- $\mathrm{NH}_{4} \mathrm{Cl}$ and harvested on to $\mathrm{GF} / \mathrm{C}$ fibre filters for liquid scintillation counting.

$\%$ phagocytosis $=\frac{\text { neutrophil-associated } \mathrm{cpm}}{\text { total } \mathrm{cpm}} \times 100$
BIOCHEMICAL STUDIES

Neutrophil hexose monophosphate shunt activity was measured by the oxidation of glucose $-1-{ }^{14} \mathrm{C}$ to ${ }^{14} \mathrm{CO}_{2} \cdot{ }^{1720}$ The assay was set up in duplicate in $25 \mathrm{ml}$ Warburg flasks with $0.2 \mathrm{ml} 15 \%$ TCA in the sidearm. The assay mixture comprised $2 \times 10^{6}$ neutrophils and $2 \times 10^{7}$ heat-killed $C$ guilliermondii in $2.0 \mathrm{ml} \mathrm{Ca}{ }^{++}$-free Kreb's Ringer phosphate + $10 \% \mathrm{AB}$ serum and $0.05 \mathrm{ml}$ glucose $-1-{ }^{14} \mathrm{C}$ $(1 \mu \mathrm{Ci}: 61 \mathrm{mCi} / \mathrm{mmol})$. Control flasks contained neutrophils or candida alone. The flasks were tightly closed with stoppers from which a piece of filter paper, soaked in $0.1 \mathrm{M}$ hyamine hydroxide, was suspended inside each flask. After $\mathbf{3 0}$ min incubation the TCA was tipped into the flasks to stop the reaction and drive the ${ }^{14} \mathrm{CO}_{2}$ out of the solution on to the filters. These were then dropped into NE 233 scintillant for liquid scintillation counting. The post-phagocytic increase in counts-per-minute (cpm) generated by the neutrophils was expressed: $\log$ increase in $\mathrm{cpm}=$

$\log _{10}$ (cpm from phagocytosing neutrophils) -

$\log _{10}$ (cpm from resting neutrophils)

Assay of neutrophil myeloperoxidase content: neutrophil preparations were freed from erythrocyte contamination by lysis with $0.85 \%$ TRIS- $\mathrm{NH}_{4} \mathrm{Cl} 8$ After washing twice, the neutrophils were resuse pended in PBS to $10 \% \mathrm{ml}$. The neutrophils in $5 \mathrm{ml}$ of this suspension were lysed by sonication, cellula debris removed by centrifugation at $1200 \mathrm{~g}$ for 7 min and the supernatant assayed spectrophotometrically for peroxidase activity according to the method of Klebanoff. ${ }^{21}$

The rate of reaction was expressed as absorbance change at $460 \mathrm{~nm} / \mathrm{min}$. Serial dilutions of horseradish peroxidase were also assayed to give a standard curve for absorbance change/min $v$ enzyme units $/ \mathrm{ml}$. The myeloperoxidase concentration in neutrophil sonicates could thus be determined.

\section{LEVAMISOLE STUDIES}

Preservative-free crystalline levamisole hydrochloride (Janssen-Pharmaceutica Ltd) was dissolved in HBSS and added to the test system to give a final concentration of $10^{-7} \mathrm{M}$. This approximates to the blood levels achieved by administration of usual doses of the drug. ${ }^{22}$ In two cases levamisole was given by mouth at a dose of $50 \mathrm{mg}$ twice daily, two days/week.

\section{STATISTICAL ANALYSIS}

The results from each assay, for all control neutrophils tested over a period of three years, were accumulated and found to fit a normal distribution pattern. ${ }^{17}$ The numbers of controls for the individual 
tests ranged from a minimum of 51 to 101 . The mean (x) standard deviation (SD), tolerance factor (TF) at the 5\% level of significance and the tolerance limits (TL) were determined for each control population. $^{23}$

$$
\mathrm{TL}=\overline{\mathrm{x}} \pm(\mathrm{SD} \times \mathrm{TF})
$$

When the results of function tests fell outside the appropriate tolerance limits, the patient was considered to have a defect in that particular in vitro function. Following the approach of Hoffman and Bullock $^{24}$ the results were expressed as indices:

LCI = leucocyte candidacidal index

LBI = leucocyte bactericidal index

LRI = leucocyte (chromium) release index

$\mathrm{PCI}=$ phagocytic (candida) index

PBI = phagocytic (bacteria) index

where index $=$

$\%$ killing or phagocytosis (patients) -

mean \% killing or phagocytosis (controls)

$\mathrm{SD} \times \mathrm{TF}$

An index $<-1 \cdot 0$ indicates significant impairment of neutrophil function.

\section{Results}

Overall, 23 of the 44 patients investigated showed defects in neutrophil microbicidal activity. The incidence of abnormalities in the diagnostic categories was: RC 8/17, RC + SC 5/8, AISA 2/4, RAEB 7/11 and CMML 1/4. Of these patients, 13 had abnormal tests at the time of presentation and 10 developed abnormalities subsequently. One of the patients with AISA (with normal tests of neutrophil function) has since developed RC and therefore moved to the RC + SC category. The distribution of values for the various indices of function at presentation is shown in Fig. 1: the incidence of abnormalities in each test was PCI $6 / 30$, LCI 3/13, LRI $7 / 40$, PBI 2/24, LBI 8/40.

Reduced microbicidal activity was associated with impaired phagocytosis in seven patients but normal phagocytosis in eight patients. In a further six patients showing impaired microbicidal activity, phagocytosis was not tested. In two patients, although neutrophils showed reduced phagocytic ability, the overall microbicidal activity was within the normal range.

The incidence of abnormal tests in the 23 patients showing impaired neutrophil function at some time during the study is shown in Table 2, together with an indication as to the occurrence of infective problems: 11 of these patients had one or more severe infections. All three patients who died of infection had RAEB. This may be contrasted with the

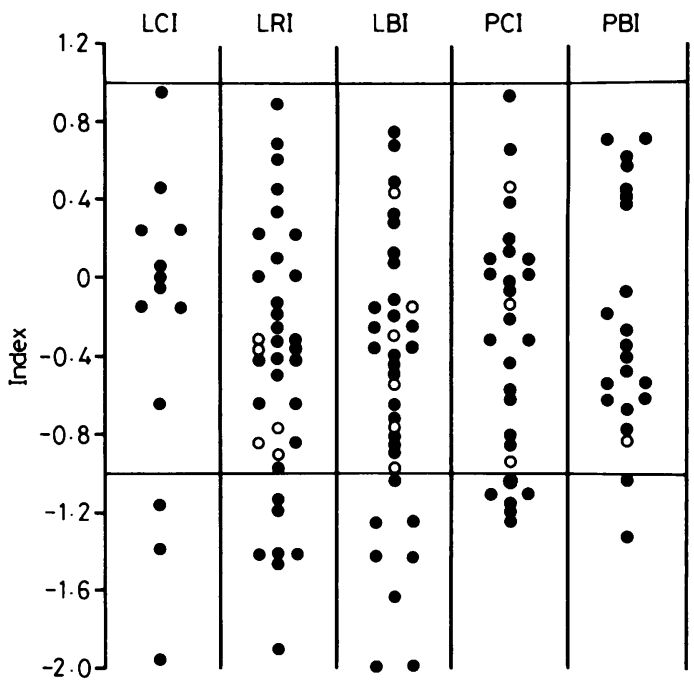

Fig. 1 Neutrophil phagocytic and microbicidal function in myelodysplastic syndromes.

LCI = leucocyte candidacidal index

$L R I=$ leucocyte (chromium) release index

$L B I=$ leucocyte bactericidal index

$P C I=$ phagocytic (candida) index

$P B I=$ phagocytic $($ bacteria $)$ index

The results are from 44 patients on the first occasion they were investigated. An index of $<-1.0$ indicates abnormal neutrophil function. $\bigcirc$ : results of subsequent assays were abnormal.

absence of severe infective problems in the 21 patients who showed no abnormalities of neutrophil function.

RELATIONS BETWEEN NEUTROPHIL FUNCTION, ABSOLUTE COUNT AND INCIDENCE OF INFECTIONS

The possibility that neutrophil function as tested in vitro might show a correlation with the absolute neutrophil count (PMN) was investigated for LCI, LRI and LBI. The correlation coefficients were as follows:

PMN $v$ LCI (46 values): $r^{2}=0.048$

PMN $v$ LRI (81 values): $r^{2}=0.078$

PMN $v$ LBI (89 values): $r^{2}=0.022$

The observed differences in neutrophil function in the groups studied could not, therefore, be attributed to differences in neutrophil count. An absolute count $<1 \times 10^{9} / 1$ was recorded in $7 / 33$ patients who had no severe infective complications and in 3/11 patients who developed severe infections. The occurrence of serious infection did not, therefore, simply reflect neutropenia. 
Table 2 Defective neutrophil function in myelodysplastic syndromes

\begin{tabular}{|c|c|c|c|c|c|}
\hline \multirow[t]{2}{*}{ Patient } & \multicolumn{4}{|c|}{ No. of abnormal tests } & \multirow{2}{*}{$\begin{array}{l}\text { Severe infective } \\
\text { problems }\end{array}$} \\
\hline & $\begin{array}{l}\text { Candida } \\
\text { phagocytosis }\end{array}$ & $\begin{array}{l}\text { Candida } \\
\text { killing }\end{array}$ & $\begin{array}{l}\text { Bacteria } \\
\text { phagocytosis }\end{array}$ & $\begin{array}{l}\text { Bacteria } \\
\text { killing }\end{array}$ & \\
\hline EW & $1 / 3$ & $3 / 6$ & $1 / 1$ & $1 / 2$ & + \\
\hline IM & $2 / 3$ & $1 / 3$ & $0 / 3$ & $0 / 3$ & + \\
\hline DS & $1 / 1$ & $1 / 1$ & $0 / 1$ & $0 / 1$ & - \\
\hline HD & $1 / 1$ & $1 / 1$ & NT & NT & - \\
\hline $\begin{array}{l}\text { MS } \\
\text { RL }\end{array}$ & $0 / 1$ & $0 / 1$ & $1 / 2$ & $1 / 2$ & + \\
\hline $\begin{array}{l}\text { RL } \\
\text { KM }\end{array}$ & $1 / 1$ & NT & $\mathrm{NT}$ & $1 / 2$ & - \\
\hline $\begin{array}{l}\mathrm{KM} \\
\mathrm{CS}\end{array}$ & $2 / 3$ & $5 / 8$ & NT & $1 / 3$ & + \\
\hline $\begin{array}{l}\text { CS } \\
\text { JS }\end{array}$ & $1 / 3$ & $1 / 3$ & $0 / 6$ & $3 / 6$ & + \\
\hline $\begin{array}{l}\text { JS } \\
\text { MC }\end{array}$ & $1 / 6$ & $7 / 12$ & $0 / 8$ & $6 / 13$ & + \\
\hline $\begin{array}{l}\text { MC } \\
\text { GC }\end{array}$ & $0 / 1$ & $0 / 3$ & $0 / 2$ & $1 / 3$ & - \\
\hline $\begin{array}{l}\text { GC } \\
\text { MG }\end{array}$ & $0 / 1$ & $1 / 1$ & $0 / 1$ & $0 / 1$ & + \\
\hline $\begin{array}{l}\text { MG } \\
\text { ED }\end{array}$ & $0 / 2$ & $2 / 2$ & $0 / 2$ & $1 / 2$ & + \\
\hline $\begin{array}{l}\text { ED } \\
\text { AM }\end{array}$ & $0 / 2$ & $0 / 4$ & $0 / 4$ & $1 / 8$ & - \\
\hline $\begin{array}{l}\text { AM } \\
\text { ES }\end{array}$ & $0 / 2$ & $0 / 5$ & $0 / 2$ & $1 / 6$ & - \\
\hline $\begin{array}{l}\text { ES } \\
\text { MF }\end{array}$ & $0 / 4$ & $1 / 3$ & $0 / 3$ & $0 / 3$ & - \\
\hline $\begin{array}{l}\text { MF } \\
\text { MCh }\end{array}$ & NT & $1 / 1$ & NT & $0 / 1$ & $+^{*}$ \\
\hline $\begin{array}{l}\text { MCh } \\
\text { BB }\end{array}$ & NT & $3 / 6$ & NT & $2 / 2$ & $+^{*}$ \\
\hline BB & NT & $1 / 2$ & NT & $2 / 2$ & $+^{*}$ \\
\hline JW & NT & $1 / 4$ & NT & $2 / 4$ & - \\
\hline $\mathbf{A H}$ & NT & $0 / 1$ & NT & $1 / 1$ & - \\
\hline JH & NT & $1 / 1$ & NT & NT & - \\
\hline $\begin{array}{l}\text { HT } \\
\text { DB }\end{array}$ & $0 / 1$ & $0 / 2$ & $1 / 2$ & $0 / 1$ & - \\
\hline DB & $1 / 1$ & $0 / 1$ & $0 / 1$ & $0 / 1$ & - \\
\hline
\end{tabular}

*Patient had infective death.

$\mathrm{NT}=$ not tested.

\section{RELATION BETWEEN NEUTROPHIL FUNCTION}

AND PERIPHERAL BLOOD MORPHOLOGY

All 44 patients showed some morphological abnormalities of the granulocyte series. In many cases there were degrees of cytoplasmic hypogranularity and sometimes apparent agranularity. Evidence of dysplasia with abnormal nuclear configuration was also common with pseudo-Pelger-Huet appearances, "cottage-loaf" nuclei and usually a marked left shift overall. There was no correlation between the degree of morphological abnormality as assessed by light microscopy and the incidence of defective function: of the 23 patients who showed functional defects, nine had marked morphological abnormalities and of 21 patients with normal function, seven had marked abnormalities in the blood film.

\section{MODULATION OF FUNCTION BY LEVAMISOLE}

In the two patients investigated in detail for the effects of levamisole, the addition of $10^{-7} \mathrm{M}$ levamisole to the assay system corrected defective candidacidal activity but had no effect on control neutrophil function or on candida viability per se (Fig. 2). This was a reproducible phenomenon.

In vitro neutrophil function was also monitored before and during the oral administration of levamisole in "therapeutic" dosage. The changes in candidacidal activity for patient $\mathrm{MCh}$, who had RAEB, are shown in Fig. 3. The LCI improved markedly after four weeks' treatment with levamisole, $100 \mathrm{mg}$, two days per week; this improvement was maintained when the dose was halved to $100 \mathrm{mg}$, one day per week. When the druog was withdrawn, function deteriorated. The enhancement of function occurred despite concomitant decrease in absolute neutrophil counts. The other patient, BB, who also had RAEB, received levamisole, $100 \mathrm{mg}$, two days per week, for a period of only four weeks after which candidacidal function, as tested by LCI, was restored to normal (from -1.97 to -0.39 ). Again function deteriorated when the drug was withdrawn.

\section{BIOCHEMICAL ASSAYS}

Six of the eight patients with normal phagocytosis but defective intracellular killing of microorganisms were investigated for their neutrophil MPO content

and/or HMPS activity.
In four of six cases (ED, AM, ES, CS) tested for MPO content there were fluctuations in both neu- $\sigma$ trophil microbicidal ability and MPO levels. The $N$ assays were repeated in parallel on several occasions and, in each instance, when function was abnormal MPO levels were reduced (Table 3 ). Two had RC and two RC + SC.

In one of five cases (GC, who had RC) tested for $\stackrel{\oplus}{\circledR}$ HMPS activity, reduced candida killing ability was associated with abnormally low post-phagocytic $\overline{0}$ HMPS activity (LRI $=-1 \cdot 18$; log increase in cpm: 


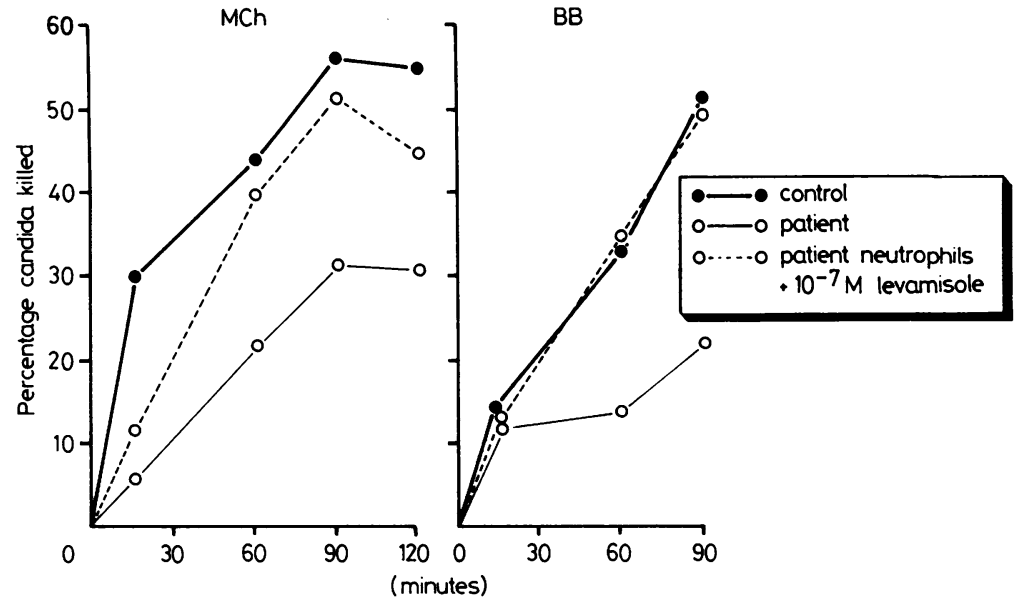

Fig. 2 Correction of the defective candidacidal function of neutrophils from two patients by levamisole. Normal control neutrophil function was not affected by levamisole. $2.5 \times 10^{6}$ neutrophils were incubated with $7.5 \times 10^{6} \mathrm{C}$ guilliermondii in HBSS $-A B$ for $60 \mathrm{~min} \pm 10^{M} \mathrm{M}$ levamisole. Candida killing was assessed by microscopic evaluation of stained smears.

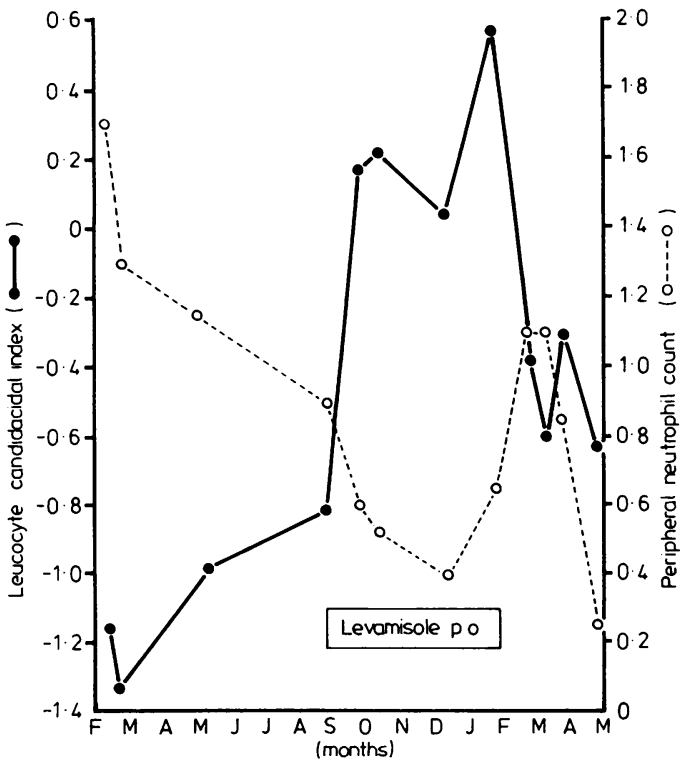

Fig. 3 Effect of oral levamisole on peripheral neutrophil count and in vitro neutrophil function

$M C h$ was on oral levamisole $50 \mathrm{mg}$ bd 2 days/week from August until December and then $50 \mathrm{mg}$ bd 1 day/week until January. $2.5 \times 10^{6}$ neutrophils were incubated with $7.5 \times$ $10^{6} \mathrm{C}$ guilliermondii in $\mathrm{HBSS}-\mathrm{AB}$ for $60 \mathrm{~min}$ and candida killing assessed by microscopic evaluation of stained smears.
$\mathrm{GC}=0 \cdot 57 ;$ control range $=0 \cdot 64-1 \cdot 65$, mean $=$ $1 \cdot 12)$.

In one case impaired microbicidal ability could not be explained by abnormalities in either MPO or HMPS activity, which were both normal.

Thirteen of the 21 patients with normal neutrophil function were tested for their MPO levels. In 12 of these 13 cases, neutrophil MPO levels were normal; one patient (WS), investigated on six occasions, was unusual in having normal tests of function but consistently low MPO levels (mean $=0.4$ enzyme units $/ 10^{6} \mathrm{PMN}$ ). He had AISA but has since developed RC + SC.

\section{Discussion}

The results of the present investigations suggest that defects in neutrophil function, as tested in vitro, are common in patients with the myelodysplastic syndromes: 23 of 44 patients had one or more neutrophil functional abnormalities when tested in vitro. In seven patients there was reduced microbicidal activity associated with impaired phagocytosis; in eight patients phagocytosis was normal but intracellular killing impaired; in six patients the overall microbicidal activity was impaired but phagocytosis was not measured; and in two patients only phagocytosis was impaired.

The broadly similar incidence of abnormalities in the main disease categories- $\mathrm{RC}, \mathrm{RC}+\mathrm{SC}$ and RAEB would suggest that such qualitative defects 
Table 3 Changes in neutrophil function and myeloperoxidase content

\begin{tabular}{|c|c|c|c|c|}
\hline Patient & Interval & $L B I$ & $L R I$ & $\begin{array}{l}M P O \\
\text { Enzyme units } / 10^{6} P M N\end{array}$ \\
\hline ED & $\frac{\tau}{6 w k}$ & $\begin{array}{l}-1.01 \\
-0.49\end{array}$ & $\begin{array}{l}\text { NT } \\
\text { NT }\end{array}$ & $\begin{array}{l}0.4 \\
2.7\end{array}$ \\
\hline $\mathrm{AM}$ & $I^{18 \mathrm{wk}}$ & $\begin{array}{l}-1.13 \\
+0.37\end{array}$ & $\begin{array}{l}\text { NT } \\
\text { NT }\end{array}$ & $\begin{array}{l}0.8 \\
2.6\end{array}$ \\
\hline ES & $13 \mathrm{wk}$ & $\begin{array}{l}\text { NT } \\
\text { NT }\end{array}$ & $\begin{array}{l}+0.43 \\
-1.3\end{array}$ & $\begin{array}{l}1.2 \\
0.7\end{array}$ \\
\hline \multirow[t]{3}{*}{ CS } & 59 wk & $-1 \cdot 25$ & -1.42 & $\begin{array}{l}0 \cdot 4 \\
0 \cdot 3\end{array}$ \\
\hline & $10 \mathrm{wk}$ & -1.21 & & 0.5 \\
\hline & 8 wk & -0.11 & -0.49 & $2 \cdot 1$ \\
\hline
\end{tabular}

LBI = leucocyte bactericidal index.

LRI = leucocyte (chromium) release index

$\mathrm{MPO}=$ myeloperoxidase (normal range $0 \cdot 7-3 \cdot 7$ : mean 1.7 enzyme units $/ 10^{6} \mathrm{PMN}$ ).

PMN = neutrophils.

NT $=$ not tested.

reflect the dysgranulopoiesis which may occur in all these disorders, whether relatively "benign" or more obviously preleukaemic. The variability of the abnormalities is consistent with data on the expression of $\mathrm{Fc}-\mathrm{IgG}$ and $\mathrm{C} 3 \mathrm{~b}$ receptors by maturing granulocytes, presumably reflecting the heterogeneity of the MDS and variation in the degree of dysgranulopoiesis. ${ }^{25}$ The demonstration of the platelet dysfunction in these patients ${ }^{26}$ is consistent with the concept of an underlying stem cell disorder which may be variably expressed in one or more cell lines. The occurrence of abnormalities in AISA supports its inclusion in the MDS "spectrum", though further studies, especially longitudinal, of patients in this category are required.

Increased susceptibility to infection is recognised as a feature of MDS and, although this may chiefly reflect neutropenia, it has been pointed out that frequent and severe infections occur in patients with normal neutrophil counts. ${ }^{34}$ This fact, and the often strikingly abnormal morphology in blood and marrow films, have encouraged the view that clinically significant qualitative abnormalities occur in these disorders although relatively few patients have been investigated. In the previous largest series of 17 patients, a tendency towards reduced neutrophil phagocytic and bactericidal activity was reported but the difference between patients and simultaneously tested controls was not striking in any of these cases, consistent with a low incidence of infective problems in this particular group. ${ }^{7}$ In the present study, patients who at some stage had severe infections also tended to show functional defects in the in vitro tests and this could not be attributed to infections as the coincidence of active infection and critical testing was avoided. Approximately half of those patients who had abnormal tests experienced such infective problems. This susceptibility to infection was probably not simply a reflection of neutropenia: low neutrophil counts were observed in patients with and without a history of recurrent infections.

The possibility that qualitative and quantitative abnormalities were directly related required consid- $\varnothing$ eration, though previous studies argued against this? no correlation between indices of function and abso lute neutrophil count was found. In view of the? complexity of the mechanisms involved it is hardly surprising that there was no correlation between morphological appearances as assessed in blood films and tests of function. Hypogranularity and in particular, myeloperoxidase (MPO) deficiency, has been put forward as the explanation for impaired microbicidal activity. ${ }^{34527}$ Of the eight patients showing defective neutrophil intracellular killing ability, six were investigated for neutrophil MPO content: four showed reduced levels at some time and coincidence with microbicidal dysfunction was observed. The findings in one other patient who had consistently normal neutrophil function and yet abnormally low MPO levels may appear to add confusion but support the concept that "back-up" killing mechanisms exist, whereby non-enzymatic microbicidal activity is increased to "compensate" for MPO deficiency. In this study the MPO estimations represented the net level of enzyme and did not distinguish subpopulations of neutrophils with differing MPO content as described by Breton-Gorius $e t$ $a l,{ }^{427}$ who suggested that in addition to an absolute deficiency of MPO in some neutrophils, the azurophil granules could show considerable variation in MPO content and that degranulation could also be defective. Whatever the mechanisms, a lack 
of MPO in the phagocytic vacuole may result in impaired microbicidal activity and variably impaired maturation in the granulocyte series ${ }^{28}$ would explain abnormalities seen in the MDS. In tests of function which assess the overall competence of neutrophil populations it is the net effect of any deficiency which will determine the result.

Although MPO deficiency may be one likely cause of dysfunction it is clear that other mechanisms concerned with phagocytosis and intracellular killing of microorganisms may also be deranged. Of five patients showing normal phagocytosis but defective intracellular killing ability who were investigated for HMPS activity, one had reduced activity. The metabolic burst, as measured by HMPS activity is triggered by perturbation of the plasma membrane during phagocytosis. It is typically defective in chronic granulomatous disease (CGD) ${ }^{29}$ associated with NADPH oxidase deficiency ${ }^{30}$ or absence of membrane-associated cytochrome b. $^{31}$ Our results imply a similar defect in our patient, as yet undefined.

We have demonstrated that levamisole, whether simply added to the test system in vitro or administered to patients in therapeutic dosage, can enhance previously depressed neutrophil function. Although the mechanism of action of levamisole is still obscure,$^{13}$ one possibility is that it may have an effect on cyclic nucleotide levels and therefore on degranulation. ${ }^{32}$ The possible link between cyclic nucleotide levels and degranulation in patients with these disorders requires further study.

The microbicidal defects found in our investigation were, in some instances, severe and approached the degree of change seen in chronic granulomatous disease. In other cases the indices of function were either mildly abnormal or at the lower end of the normal range. While it is difficult to assess the clinical significance of in vitro tests, particularly in the "grey area" of mild abnormality, there was a striking correlation between the findings of clear-cut neutrophil defects and the liability to severe infections. It has been suggested that even mild functional defects may assume importance at low neutrophil counts. ${ }^{33}$ Furthermore, micro-organisms which are not killed following ingestion may be readily disseminated. ${ }^{34}$ Impaired neutrophil function is probably an important factor underlying lifethreatening infections in this category of patient. It would seem worthwhile to monitor neutrophil function in the MDS in order to identify patients who may be particularly at risk. Although improved methodology makes the simultaneous investigation of several aspects of function feasible it can be difficult, and is sometimes impossible, to carry out a complete range of tests in patients who are also severely neutropenic; close monitoring of such patients will require further technical advances.

The authors are grateful for the encouragement and support of Professor EM Cooke, Professor DH Watson, Dr BE Roberts and Dr C Toothill.

The study was supported by grants from the Special Trustees, Leeds General Infirmary and the Yorkshire Cancer Research Campaign.

\section{References}

' Dacie JV, Smith MD, White JC, Mollin DL. Refractory normoblastic anaemia: a clinical and haematological study of seven cases. Br J Haematol 1959;5:56-82.

${ }^{2}$ Linman JW, Bagby GC. The preleukemic syndrome (hemopoietic dysplasia). Cancer 1978;42:854-64.

${ }^{3}$ Breton-Gorius J, Houssay D, Vilde JL, Dreyfus B. Partial myeloperoxidase deficiency in a case of preleukaemia. II. defects of degranulation and abnormal bactericidal activity of blood neutrophils. Br J Haematol 1975;30:279-88.

${ }^{4}$ Breton-Gorius J, Coquin Y, Vilde JL, Dreyfus B. Cytochemical and ultrastructural studies of aberrant granules in the neutrophils of two patients with myeloperoxidase deficiency during a preleukaemic state. Blood Cells 1976;2:180-209.

${ }^{5}$ Lehrer RI, Goldberg LS, Apple MA, Rosenthal NP. Refractory megaloblastic anemia with myeloperoxidase deficient neutrophils. Ann Intern Med 1972;76:447-53.

${ }^{6}$ Solberg CO, Schreiner A, Hellum KB, Hamre E. Neutrophil granulocyte function in the early diagnosis of acute myelomonocytic and myeloblastic leukaemia. Acta Med Scand 1975;197:147-51.

${ }^{7}$ Ruutu P, Ruutu T, Vuopio P, Kosunen TU, De La Chappelle A. Function of neutrophils in preleukaemia. Scand $J$ Haematol 1977;18:317-25.

- Houghton JB. Neutrophil function and diagnosis of preleukaemic states. Postgrad Med J 1979;55:396-9.

9 Sultan C, Pierre RV, Hast R, Imbert M. Refractory anemias and dysmyelopoietic syndromes (DMPS). In: McArthur JR, ed: Hematology/Hematologie Transfusion 1980. The education program of the American Society of Hematology, 1980:22.

${ }^{10}$ Bennett JM, Catovsky D, Daniel MT, Flandrin G, Galton DAG, Gralnick HR, Sultan, C. The French-American-British (FAB) Co-operative Group. Proposals for the classification of the myelodysplastic syndromes. Br J Haematol 1982;51:189-99.

${ }^{11}$ Boyum A. Separation of leucocytes from blood and bone marrow. Scand J Clin Lab Invest 1968;21:suppl 97.

${ }^{12} \mathrm{El}$-Maallem H, Fletcher J. Defective neutrophil function in chronic granulocytic leukaemia. Br J Haematol 1976;34:95103.

${ }^{13}$ Child JA, Martin S, Cawley JC, Ghoneim ATM. Defective microbidical function of neutrophils in haematological malignancies and lymphomas: correction by levamisole in vitro. Biomedicine 1978;29:159-61.

14 Yamamura M, Boler J, Valdimarsson H. A ${ }^{51}$ chromium release assay for phagocytic killing of Candida albicans. J Immunol Methods 1976;13:227-33.

15 Martin S, Ghoneim ATM, Child JA. A new neutrophil candida killing test: ${ }^{\text {s1 }}$ chromium release from Candida guilliermondii. $J$ Clin Pathol 1980;33:757-61.

16 Yamamura M, Boler J, Valdimarsson H. Phagocytosis measured as inhibition of uridine uptake by Candida albicans. J Immunol Methods 1977;14:19-24.

${ }^{17}$ Martin S. Study of neutrophil function in haematological malignancies. University of Leeds: PhD thesis, 1981.

${ }^{18}$ Solberg CO. Influence of phenylbutazone on the phagocytic and 
bactericidal activities of neutrophil granulocytes. Acta Pathol Microbiol Scand [B] 1974;82:258-62.

19 Verhoef J, Peterson PK, Quie PG. Kinetics of staphylococcal opsonization, attachment, ingestion and killing by human polymorphonuclear labelled bacteria. J Immunol Methods 1977;14:303-11.

${ }^{20}$ Odeberg H, Olofsson T, Olsson I. Granulocyte function in chronic granulocytic leukaemia: bactericidal and metabolic capabilities during phagocytosis in isolated granulocytes. $\mathrm{Br} \mathrm{J}$ Haematol 1975;29:427-41.

${ }^{21}$ Klebanoff SJ. Inactivation of rat uterine preparation. Endocrinology 1965;76:301-11.

${ }^{22}$ Symoens J. Levamisole, an antiangergic chemotherapeutic agent, an over view. In: Chirigos MA, ed. Control of neoplasia by modulation of the immune system. New York: Raven Press, 1977:1-24.

${ }^{23}$ Eisenhart H, Hastay W, Wallis D. Techniques in statistical analysis. London: McGraw-Hill Book Company, 1947.

${ }^{24}$ Hoffman TA, Bullock WE. A statistical approach to the polymorphonuclear leukocyte bactericidal assay. J Lab Clin Med 1973;81:148-56.

${ }^{25}$ Bynoe AG, Scott CS, Hough D, Roberts BE. Granulocyte Fc-IgG and $\mathrm{C} 3 \mathrm{~b}$ receptor expression in the primary myelodysplastic syndromes (MDS)-relationship with dysgranulopoiesis and evidence for heterogeneity within morphological subgroups. Submitted for publication.

${ }^{26}$ Pamphilon DH, Roberts BE, Davies JA. Platelet dysfunction in myelodysplastic syndromes (MDS) (Abstract). Br J Haematol 1983. (in press.)

${ }^{27}$ Breton-Gorius J, Houssay D, Dreyfus B. Partial myeloperoxidase deficiency in a case of preleukaemia. I. Fine structure and myeloperoxidase synthesis of promyelocytes. $\mathrm{Br} \mathrm{J}$ Haematol 1975;30:273-8.

${ }^{28}$ Breton-Gorius J. Abnormalities of granulocytes and megakaryocytes in preleukaemia syndromes. In: Schalzl F, Hellriegel K-P, eds. Preleukaemia. Berlin: Springer, 1979:24-34.

${ }^{29}$ Holmes B, Page AR, Windhorst DB, Quie PG, White JG, Good RA. The metabolic pattern and phagocytic function of leukocytes from children with chronic granulomatous disease. Ann NY Acad Sci 1968;155:888-901.

${ }^{30}$ Hohn DC, Lehrer RI. NADPH oxidase deficiency in X-linked chronic granulomatous disease. J Clin Invest 1975;55:707-13.

${ }^{31}$ Segal AW, Jones OTG. Absence of cytochrome b reduction in stimulated neutrophils from both female and male patients with chronic granulomatous disease. FEBS Letters 1980;110:111-4.

${ }^{32}$ Anderson R, Glover A, Koornhof JH, Rabson AR. In vitro stimulation of neutrophil motility by levamisole: maintenance of cGMP levels in chemotactically stimulated levamisole-treated neutrophils. J Immunol 1976;117:428-32.

${ }^{33}$ Child JA, Martin S, Robinson AE, Ghoneim ATM. Microbicidal function of neutrophils from patients with leukaemia and lymphomas and from donors: therapeutic implications. Exp Hematol 1978;6 suppl 3:103.

${ }^{34}$ Cline MJ. Defective mononuclear phagocytic function in patients with myelomonocytic leukemia and in some patients with lymphoma. J Clin Invest 1973;52:2185-90.

Requests for reprints to: Dr JA Child, Department of Haematology, Leeds General Infirmary, Leeds LS1 3EX, England. 